\title{
Air Compressor Station System Simulation
}

\author{
Gao Peichuan \\ Nanjing institude of technology \\ Nanjing China
}

\begin{abstract}
Will design a good air compressor station system dynamic simulation run, will run process shows that for air compressor station design offer help and reference. Through the use of configuration software (KingView) complete air compressor station system simulation to verify the performance of the system, the unreasonable parts modified, improve the system characteristics.
\end{abstract}

Keywords-Air compressor station; Mathematical modeling; The simulation

\section{INTRODUCTION}

Along with the unceasing improvement of the level of scientific research, the science and technology unceasing development, the rationality of the design of product requirements can't satisfy the demand, which requires the continuous perfect design method, therefore engineering design expert system arises at the historic moment, and become the development direction of modern engineering design. Using expert system for air compressor station system design, in order to user input data and information on the basis of the actual situation of the air compressor station are analyzed, looking for design problems are given solutions, rapidly and accurately determine the air compressor station system reasonable configuration, and then to design good air compressor station system simulation run, recreating the actual running condition, to provide the reference for design decisions. Air compressor station expert system composition as shown in figure 1 shows.

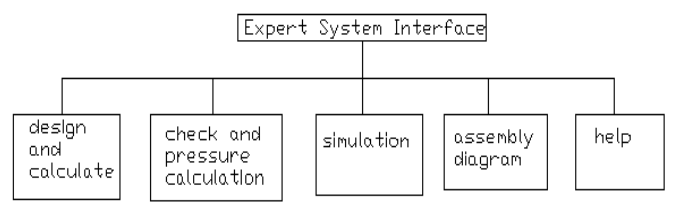

Figure 1

This paper mainly introduces air compressor station design dynamic simulation, computer multimedia advantage that it can be accurate operation, convenient and quick, the use of text, graphics, curve and so on many kinds of ways, methods the user the designed air compressor station system performance and process can more directly displayed.

\section{A System development environment}

Windows 98 and Windows 2000 operating system development environment in the software design, the application of Powerbuilder version 8.0 as a development tool, the system simulation development using KingView configuration king method. In the process of design system, the first expert system interface design, and then the specific design of air compression station. System design set up simulation module, with kingview software to do the simulation interface, the interface of the simulation is the content of air compressor station system in the operation pressure, flow rate, temperature of the specific relationship and trend. The specific design process for: so to establish the pipeline internal pressure, gas flow rate, temperature mathematical function relation model, for the expert system to provide theoretical basis for design simulation. In sino-german cooperation, modern manufacturing engineering center air compressor station system design for simulation and demonstration, simulation object, to the actual working condition

Analysis: (1) empty press start to tank air condition, and at the same time, the gas point gas situation according to their respective conditions for work. (2) the tank in the row, the bleed work in the process of the tank pressure, temperature, flow changes, and actual working condition, the dynamic simulated appeared.

\section{B 7 ank to fill, bleed mathematical model}

\section{1) Adiabatic air mathematical model}

Pressure for $P_{1}$, temperature for $T_{1}$ constant air supply, through the flow characteristic parameters for $\mathrm{S}$ and $\mathrm{b}$ pneumatic element (or loop), to the initial pressure for $\mathrm{P}_{20}$, initial temperature for $\mathrm{T}_{20}\left(\right.$ set $\left.\mathrm{T}_{20}=\mathrm{T}_{1}\right)$, volume for $\mathrm{V}$ container gas, as shown in figure 2 shows.

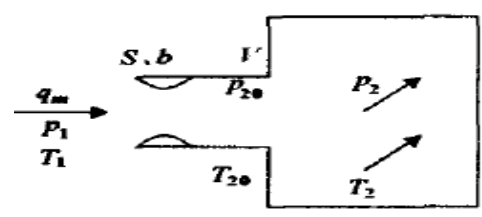

Figure 2

On the previous illustration constant volume adiabatic air, available

$$
\left(1-\frac{1}{\mathrm{~K}} \cdot\left(\frac{\mathrm{T}_{2}}{\mathrm{~T}_{1}}\right)\right) \cdot \frac{\mathrm{d}_{\mathrm{p} 2}}{\mathrm{p}_{2}}=\frac{\mathrm{dT}_{2}}{\mathrm{~T}_{2}}
$$

\section{SYSTEM DEVELOPMENT}


Integral to

$$
\mathrm{p}_{2}=\frac{\mathrm{CT} \mathrm{T}_{2}}{1-\frac{\mathrm{T}_{2}}{\mathrm{KT_{1 }}}}(2)
$$

Will cavity indoor initial state $\mathrm{P}_{1}=\mathrm{P}_{20}, \mathrm{~T}_{2}=\mathrm{T}_{20}=\mathrm{T}_{1}$ generation into the type to integral constantis $\mathrm{C}=\frac{(\mathrm{K}-1) \mathrm{p}_{20}}{\mathrm{KT}_{20}}$ on type into

$$
\begin{aligned}
& \frac{\mathrm{p}_{2}}{\mathrm{p}_{20}}=\frac{(\mathrm{K}-1) \mathrm{T}_{2}}{K \mathrm{~T}_{1}-\mathrm{T}_{2}}=\frac{(\mathrm{K}-1) \mathrm{T}_{2}}{\mathrm{KT}_{20}-\mathrm{T}_{2}} \\
& \text { or } \frac{\mathrm{T}_{2}}{\mathrm{~T}_{20}}=\frac{\mathrm{K}}{1+\frac{(\mathrm{K}-1) \mathrm{D}_{20}}{\mathrm{D}_{2}}}
\end{aligned}
$$

Visible, with the outside heat without the constant volume of aeration process is polytropic process.

Will type $\mathrm{dm}=\mathrm{qm} * \mathrm{dt}$ application in figure 2 fixed volume adiabatic air, can write

$$
\mathrm{q}_{\mathrm{m}}=\frac{\mathrm{dm}}{\mathrm{dt}}=\frac{\mathrm{d}}{\mathrm{dt}}\left(\frac{\mathrm{p}_{2} \mathrm{~V}}{\mathrm{RT}_{2}}\right)
$$

Will type (3) generation into the type, elimination T2 to:

$$
q_{m}=\frac{V \mathrm{dp}_{2}}{\mathrm{KRT}_{1} \mathrm{dt}}
$$

In the choked flow state of the effective sectional area $\mathrm{S}$ value and the critical pressure ratio $b$ value two characteristic parameters can also complete expression of the characteristic flow pneumatic components. Known $\mathrm{S}$ and $\mathrm{b}$ value, can press the calculation formula in various pressure difference by pneumatic components of mass flow.

$$
\mathrm{q}_{\mathrm{m}}=\mathrm{p}_{1} \mathrm{~S} \cdot\left(\frac{2}{\mathrm{k}+1}\right)^{\frac{\mathrm{k}+1}{2(\mathrm{k}-1)}} \cdot \sqrt{\frac{\mathrm{k}}{\mathrm{RT}_{1}}}=0.04 \frac{\mathrm{p}_{1}}{\sqrt{\mathrm{T}_{1}}} \mathrm{~S}
$$

At the time $\frac{p_{2}}{p_{2}} \leq b$ for sound velocity gas by type (5) substitution type $(4)$, the integral, proper p 20 imitation to p 2 the aeration time

$$
\mathrm{t}=\frac{1.4603 \mathrm{~V}}{K S \sqrt{R T_{1}}} \cdot\left(\frac{\mathrm{p}_{2}}{\mathrm{p}_{1}}-\frac{\mathrm{p}_{20}}{\mathrm{p}_{1}}\right)
$$

\section{2) Adiabatic blow-off mathematical model}

Variable volume of adiabatic blow-off process is isentropic process, of course, constant volume of adiabatic blow-off process is isentropic process, namely adiabatic blow-off process, container absolute pressure and temperature relationship submits type (7).

$$
p=C T \frac{K}{k-1}
$$

Set volume for $\mathrm{V}$ container, initial pressure for $\mathrm{p} 10$, initial temperature for T10, through the flow characteristic parameters for $\mathrm{S}$ value and $\mathrm{b}$ value of the pneumatic components (or loop), to pressure for $\mathrm{p} 2$ external deflation, as shown in figure 3 shows.

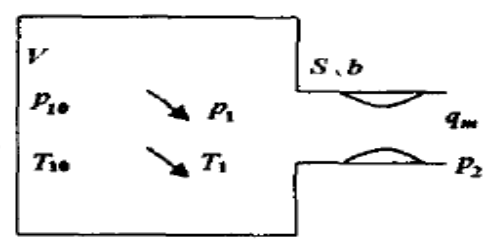

Figure 3

Will the tank of initial state parameter $\mathrm{p}_{10}, \mathrm{~T}_{10}$ substitution type (7), the adiabatic put when gas container pressure $\mathrm{p} 1$ and $\mathrm{T} 1$ of relation for

$$
\frac{\mathrm{p}_{10}}{\mathrm{p}_{1}}=\left(\frac{\mathrm{T}_{10}}{\mathrm{~T}_{1}}\right) \frac{\mathrm{K}}{\mathrm{K}-1}
$$

Will type $\mathrm{dm}=-$ qmdt substitution application in as shown in figure 3 constant volume adiabatic deflation, can write

$$
\mathrm{q}_{\mathrm{m}}=-\frac{\mathrm{dm}_{1}}{\mathrm{dt}}=-\frac{\mathrm{d}}{\mathrm{dt}}\left(\frac{\mathrm{p}_{1} \mathrm{~V}}{\mathrm{RT}_{1}}\right)=-\frac{\mathrm{Vd}}{\mathrm{Rdt}}\left(\frac{\mathrm{p}_{1}}{\mathrm{~T}_{1}}\right)
$$

Will type (8) generation into the type, finishing have to

$$
\mathrm{q}_{\mathrm{m}}=\frac{\mathrm{Vdp_{1 }}}{\mathrm{KRT}_{1} \mathrm{dt}}
$$

At the time $\frac{p_{2}}{p_{1}} \leq b$ for sound velocity, bleedMartial $\mathrm{qm}=0.04 \frac{\mathrm{p}_{2}}{\sqrt{\mathrm{T}}}$ Substituting type (9), The integral, when $\mathrm{p} 10$ down to $\mathrm{p} 1^{1}$ time required

$$
\mathrm{t}=\frac{7.3016 \mathrm{~V}}{\mathrm{~S} \cdot\left(\left(\frac{\mathrm{P}_{10}}{\mathrm{P}_{1}}\right)^{\frac{1}{7}}-1\right) \cdot \sqrt{\mathrm{RT}_{10}}}
$$

\section{THE SIMULATION DESIGN SOFTWARE}

In order to dynamic simulation shows that air compressor station system of operation, the application of Beijing and control technology development CO. LTD. Of kingview 6.0 software to simulate the demo. Kingview 6.0 is completely based on the concept of network, support real client/server mode and Internet/Intranet web browser technology, and is a kind of telescopic flexible structure, according to the network size, can different site design into the I/O server, alarm server, data server, login server, timing server, client, etc., in system expansion and change, has great flexibility. Kingview 6.0 design perfect $\mathrm{YuJieG}$ ou redundancy, in five level provides redundant: I/O channel redundancy, double equipment redundancy, double network redundancy, double machine 
redundancy, double system redundancy. Kingview 6.0 design into a complete sense of software platform,Allows the user to function expansion and play, it is a ActieX container without programming can be directly connected to the third party control configuration WangZhong; Kingview 6.0 is not only the OPC client, or OPC server, to support any OPC client software to provide data; Kingview 6.0, alarm information can be directly output to take ODBC interface database, such as Access, SQL Server, etc.; Also provides a set of dynamic link libraries, allows users to use VB, VC direct access configuration king database, and constructing function more powerful industrial control system; Kingview 6.0 can also and King - PLC110 fully integrated up, can do it KingPLC110 in the backgroundControl, configuration king at the front desk for human-computer interface display. In version 5.1 the insufficiency, configuration king 6.0 redesigned the report system and the library system. But with Excel comparable embedded statements, powerful and easy to use; All library all update, has the dynamic change graphics appearance animation elves; Graphics system increases the infinite color and transition color; Communication system increase online connection, fault diagnosis, remote dial-up and many practical auxiliary tool. Kingview 6.0 has reached or exceed foreign high-grade imported software almost all of the functions, and in many ways more suitable for China's user's characteristics and requirements. For example, accumulative algorithm, multiple linear, embedded statements, remote dial-up, animation connection wizard, special animation effects, etc. Kingview 6.0 is the crystallization of the collective wisdom, division of labor cooperation Results, and control the company's enterprise culture effectively safeguard it, USES the advanced based on/milestone 0 software development organization model, the numerous software engineer effectively organization to together, make large software research and development of any error in the exposed early and overcome them, still have designed a lot of software test case continuously, the purpose is the user to get a stable quality and reliable products.

\section{AIR COMPRESSOR STATION SIMULATION SYSTEM APPLICATION}

Air compressor station simulation system to sino-german cooperation, modern manufacturing engineering center air compressor station system as an example: for aeration process is shorter, and the outside world basic no heat exchange, and that empty press for a constant pressure and constant temperature air, so use front tank charge and discharge gas mathematical formula, namely, charge and discharge gas is in the adiabatic cases, air compressor outlet pressure is $0.75 \mathrm{MPa}$, air compressor exit temperature of $60{ }^{\circ} \mathrm{C}$, tank volume $1 \mathrm{~m} 3$, put gas end pneumatic element choked flow state of the effective sectional area for 400 was the best callus induction, air tank initial pressure is $0.1 \mathrm{MPa}$, initial temperature $20{ }^{\circ} \mathrm{C}$. Numerical calculation is based on sound velocity bleed for the premise.

Air compressor station simulation system to sino-german cooperation, modern manufacturing engineering center air compressor station system as an example: for aeration process is shorter, and the outside world basic no heat exchange, and that empty press for a constant pressure and constant temperature air, so use front tank charge and discharge gas mathematical formula, namely, charge and discharge gas is in the adiabatic cases, air compressor outlet pressure is $0.75 \mathrm{MPa}$, air compressor exit temperature of $60{ }^{\circ} \mathrm{C}$, tank volume $1 \mathrm{~m} 3$, put gas end pneumatic element choked flow state of the effective sectional area for 400 was the best callus induction, air tank initial pressure is $0.1 \mathrm{MPa}$, initial temperature $20{ }^{\circ} \mathrm{C}$. Numerical calculation is based on sound velocity bleed for the premise.

\section{A Aration process}

By type (3) type (6) have to

$$
\begin{gathered}
\mathrm{T} 2=\frac{\mathrm{KT} 20 \mathrm{p}_{2}}{\mathrm{p} 2+(\mathrm{K}-1) \mathrm{p} 2 \mathrm{C}} \\
\mathrm{p} 2=\frac{\mathrm{tg}}{\mathrm{P} 1 \sqrt{\mathrm{RT}_{1}}} \\
1.4603
\end{gathered}
$$

Make program execution time of $1 \mathrm{~s}$, then $1 \mathrm{~s}$ to run the program a get a pressure and temperature, therefore, $1 \mathrm{~s}$ after the pressure set to $\mathrm{PC}$, temperature of Tc, then

$$
\begin{gathered}
\mathrm{p}^{\prime}=10 \times(\mathrm{p} 2+0.089) \\
\mathrm{T}^{\prime}=0.14 \times \frac{\mathrm{p} 2}{(0.14 \mathrm{p} 2-0.0356)} \cdot \mathrm{T} 20
\end{gathered}
$$

\section{B Blow-ofj process}

By type (9) with type (8) have to

$$
\begin{gathered}
\mathrm{p} 1=\frac{(7.3016 \mathrm{~V}))^{7}}{\left(\mathrm{tS} \sqrt{\mathrm{RT}_{10}}+7.3016 \mathrm{~V}\right)} \cdot \mathrm{p} 10 \\
\mathrm{~T} 1=\left(\frac{\mathrm{p} 1}{\mathrm{p} 10}\right)^{\frac{\mathrm{K}}{\mathrm{K}-1}-\mathrm{T} 10}
\end{gathered}
$$

We make program execution time of $1 \mathrm{~s}$, then $1 \mathrm{~s}$ to run the program a get a pressure value and temperature value, therefore, $1 \mathrm{~s}$ after the pressure set to $\mathrm{p}$ ", temperature for $\mathrm{T}$ ", then

$$
\mathrm{p}^{\prime \prime}=\left(\frac{7.3016}{400 \mathrm{x}(10)^{-6} \mathrm{x} \sqrt{287 \mathrm{~T}_{10}}+7.3016}\right)^{7} \mathrm{xp} 10
$$

\section{The main interface shown as shown in figure 4}




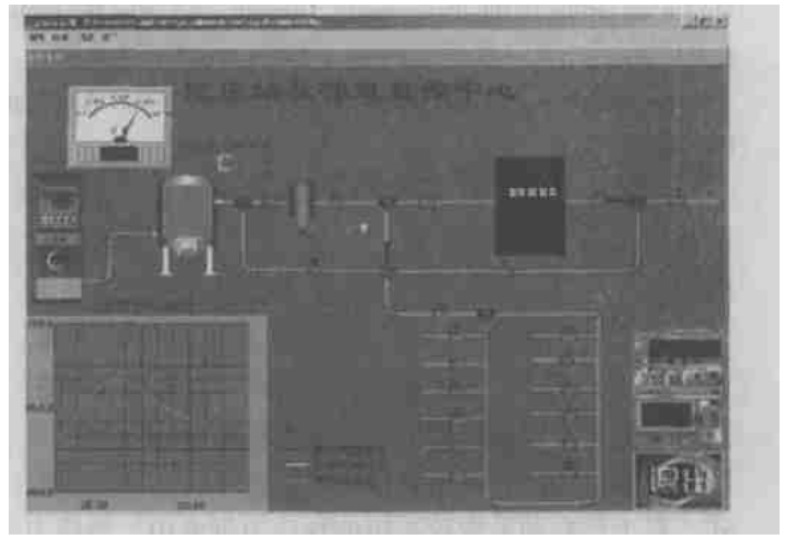

Figure 4

\section{The program code}

If (empty press switch $==1$ )

\{

If $(\mathrm{a}==0)$

\{

If (tank pressure $>=04 \& \&$ tank pressure $<=05)$

\{

Tank pressure $=($ tank pressure +0089$) * 10$;

Tank temperature $=014 *$ tank pressure $/(014 *$ tank pressure

Force - 00356) * tank temperature;

$\mathrm{A}=1$;

else

\{

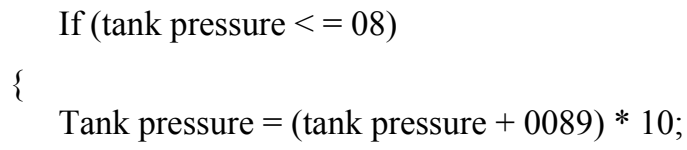

Detailed procedure slightly

\section{E Every trend curve}

Every trend curve can separate said can also said in the home plane, as shown in figure 4 shows, three curve were expressed as temperature change, pressure change, flow change trend curve. History curve narrative slightly.

\section{SUMMARY}

The compressed air station expert system to provide a design platform for the actual air compressor station system design and can be used for the air compressor station system, and simulation help make up for the deficiency of the design personnel practical experience, facilitate the promotion of design standard and international standards. The expert system for air compressor station system design can not only make the system configuration reasonable and reduce the manufacturing cost, and can realize energy saving and reduce the cost. Already the compressed air station expert system will sino-german cooperation, modern manufacturing engineering center air compressor station system for the actual simulation, operation.

\section{REFERENCES}

[1] ZhangHongJia 1 hydraulic and pneumatic transmission 1 Beijing: mechanical industry publishing house, 20001

[2] SMC co., LTD., a modern practical pneumatic technology 1 Beijing: machinery industryPress, 19981

[3] HeXuHong 1 powerbuilder810 database system development strength navigation 1 northBeijing: people's post and telecommunications university press, 20031 